\title{
A Numerical Simulation of Nocturnal Drainage Flow
}

\author{
By Tetsuji Yamada \\ Radiological and Environmental Research Division \\ Argonne National Laboratory, Argonne, IL 60439 \\ (Manuscript received 26 May 1980, in revised form 13 September 1980)
}

\begin{abstract}
A three-dimensional mesoscale atmospheric model, previously used to simulate airflow over cooling ponds and hypothetical, simplified mountains, has been modified to simulate development of nocturnal drainage flow in realistic terrain, part of the California Geysers area. Turbulent fluxes appearing in the governing equations for mean variables are computed from simplified second-moment turbulence-closure equations where only a turbulence energy equation and a master-length scale equation are solved prognostically. Qualitative simulation of drainage flow, horizontal covergence in the valley, and resulting vertical motions are satisfactory. Simulated wind speeds near the surface are greater than observed values, possibly due to inadequate resolution of observations or to a lack of consideration of the drag associated with canopy flow.
\end{abstract}

\section{Introduction}

One of the objectives of the Atmospheric Studies in Complex Terrain (ASCOT) program of the U.S. Department of Energy, is to improve modeling of transport and diffusion of energyrelated pollutants over terrain typical of areas of energy development. An initial ASCOT field experiment to investigate nocturnal drainage flow, conducted during summer 1979 over an area designated as the California Known Geothermal Resources Area (KGRA), provides data which can be compared with model simulations of wind flows.

Analytical solutions for density driven slope flow have been obtained under special conditions in which various simplifications can be assumed (e.g., see Sutton, 1953). The most critical assumption in the theory is one-dimensional flow, i.e., the flow is assumed to be uniform except in the direction perpendicular to the surface. Eddy viscosity and eddy diffusivity are also assumed to be constant. Despite these simplifications, wind profiles predicted by the theory agree qualitatively with field data such as that obtained at Innsbruck, Austria (Sutton, 1953). Analytical solutions for a two-dimensional case in which quantities vary tangentially as well as normally to the slope have been obtained for mountain lee-wave flow. However, velocities in layers close to the surface, such as in the case of nocturnal drainage flow, are difficult to obtain, since the boundary conditions at the surface are quite complex. Thus, analytical solutions are often replaced by numerical solutions obtained with finite-difference or finite-element methods.

The complex topography in the Geysers geothermal area results in highly variable wind and turbulence fields. Vertical motion, shear-generated turbulence and meandering of horizontal winds in the Geysers area are all important for realistic simulations of dispersion of hydrogen sulfide released into the atmosphere during conversion of geothermal energy into electric power. Three-dimensional mesoscale models that consider the effects of topography have been proposed (e.g., Anthes and Warner, 1974; Mahrer and Pielke, 1975; Nickerson, 1979). However, none of the models have been applied to an area whose horizontal scale is as small as that studied here, and most existing models use a simple expression for eddy viscosity (e.g., O'Brien, 1970) for parameterization of turbulence. O'Brien's formula requires specification of the boundary layer height. Estimation of boundary layer heights over rugged terrain is difficult, particularly when the atmosphere is stably stratisfied. 
In this study, a three-dimensional, simplified second-moment turbulence-closure model, previously used to simulate airflow over Gaussianshaped mountains (Yamada, 1978b) and a large cooling pond (Yamada, 1979), has been modified to simulate nocturnal drainage flow over the Geysers area. Results are compared with the wind data collected during the 1979 field experiment, briefly reviewed in the following section.

\section{Initial ASCOT field experiment}

The first preliminary field experiment under ASCOT was conducted in July 1979 over an area approximately $10 \mathrm{~km} \times 7 \mathrm{~km}$ (Fig. 1) in the California KGRA, approximately $130 \mathrm{~km}$ north of San Francisco. The area is surrounded by three mountains, Boggs Mountain (elevation approximately $1000 \mathrm{~m}$ ) to the north, Cobb Mountain $(\sim 1300 \mathrm{~m})$ to the northwest and Pine Mountain $(\sim 1000 \mathrm{~m})$ to the southwest, which form a valley opening toward the east-southeast. Surface vegetation is heterogeneous, varying from dense forest to almost bare soil. However, at present, no quantitative information on the distribution of surface vegetation is available. Five National Laboratories and other institutions participated in the experiment, which lasted approximately two weeks. Vertical profiles of mean wind, mean temperature, and mean water vapor up to $525 \mathrm{~m}$ above the ground were. measured hourly at two sites by tethered sondes from sunset to sunrise. Additional wind profiles were obtained with a doppler acoustic sounder and pibals. Winds averaged over a $600 \mathrm{~m}$ path were

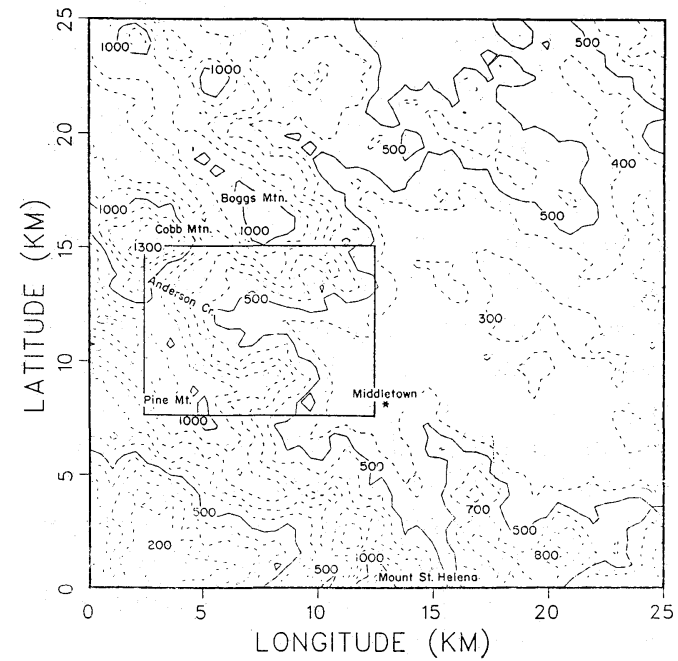

Fig. 1 Topography in the Geysers area. Simulations are performed over the area enclosed. recorded by a laser anemometer. Winds at $10 \mathrm{~m}$ above the ground were measured hourly at seven towers deployed in the area. These data are used in Section 7 to evaluate model results.

\section{Model equations}

For simulations of flows over nonhomogeneous surface boundaries, a terrain following vertical coordinate system is often used in order to simplify the treatment of boundary conditions. Here the transformation used by Mahrer and Pielke (1975) is adopted:

$$
z^{*}=\bar{H}\left(z-z_{g}(x, y)\right) /\left(H(x, y, t)-z_{g}(x, y)\right),
$$

where $z^{*}$ and $z$ are the transformed and Cartesian vertical coordinates, respectively; $z_{g}(x, y)$ is ground elevation; $H(x, y, t)$ is the material surface top of the model and $\bar{H}$ is the initial value of $H$. It is noted that $z^{*}$ is directed vertically and may not be perpendicular to the ground.

The governing equations, following the coordinate transformation, are*

$$
\begin{aligned}
& D U / D t=f\left(V-V_{g}\right)+g\left(\bar{H}-z^{*}\right)(\bar{H})^{-1} \\
& \times\left[1-\left\langle\Theta_{v}\right\rangle \Theta_{v}{ }^{-1}\right] \partial z_{g} / \partial x \\
& +g\left[\left\langle\Theta_{v}\right\rangle\left\langle\Theta_{v}(\bar{H})\right\rangle^{-1}\right. \\
& \left.-\left(\left\langle\Theta_{v}\right\rangle \Theta_{v}^{-1}-1\right) z^{*}(\bar{H})^{-1}-1\right] \cdot \partial H / \partial x \\
& +\partial\left(K_{x} \partial U / \partial x\right) / \partial x+\partial\left(K_{x y} \partial U / \partial y\right) / \partial y \\
& +\bar{H}\left(H-z_{g}\right)^{-1} \partial(-\overline{u w}) / \partial z^{*}, \\
& D V / D t=-f\left(U-U_{g}\right) \\
& +g\left(\bar{H}-z^{*}\right)(\bar{H})^{-1}\left[1-\left\langle\Theta_{v}\right\rangle \Theta_{v}^{-1}\right] \partial z_{g} / \partial y \\
& +g\left[\left\langle\Theta_{v}\right\rangle \cdot\left\langle\Theta_{v}(\bar{H})\right\rangle^{-1}\right. \\
& \left.-\left(\left\langle\Theta_{v}\right\rangle \Theta_{v}{ }^{-1}-1\right) z^{*}(\bar{H})^{-1}-1\right] \partial H / \partial y \\
& +\partial\left(K_{x y} \partial V / \partial x\right) / \partial x+\partial\left(K_{y} \partial V / \partial y\right) / \partial y \\
& +\bar{H}\left(H-z_{g}\right)^{-1} \partial(-\overline{v w}) / \partial z^{*}, \\
& \partial U / \partial x+\partial V / \partial y+\partial W^{*} / \partial z^{*} \\
& -\left(H-z_{g}\right)^{-1}\left(U \cdot \partial z_{g} / \partial x+V \partial z_{g} / \partial y\right) \\
& +\left(H-z_{g}\right)^{-1}(\partial H / \partial t+U \partial H / \partial x \\
& +V \partial H / \partial y)=0
\end{aligned}
$$

where

$$
\begin{aligned}
& W^{*} \equiv \bar{H}\left(H-z_{q}\right)^{-1} W-z^{*}\left(H-z_{g}\right)^{-1} \\
& \quad \times(\partial H / \partial t+U \partial H / \partial x+V \partial H / \partial y) \\
& \quad+\left(z^{*}-\bar{H}\right)\left(H-z_{g}\right)^{-1}\left(U \partial z_{g} / \partial x+V \partial z_{g} / \partial y\right),
\end{aligned}
$$

* Derivations of (2), (3), (8), and (9), and the assumptions used are found in the Appendix. A list of symbols is also provided in the Appendix. 
and

$$
\begin{aligned}
& D(\quad) / D t \equiv \partial(\quad) / \partial t+U \partial(\quad) / \partial x \\
&+V \partial(\quad) / \partial y+W \partial() / \partial z \\
&= \partial(\quad) / \partial t+U \partial(\quad) / \partial x+V \partial(\quad) / \partial y \\
&+W * \partial(\quad) / \partial z^{*} .
\end{aligned}
$$

In the above expressions $<>$ indicates an average over a horizontal surface.

A prognostic equation for $H$ may be obtained by integrating the equation of continuity (4) from the surface to $\bar{H}$ (Mahrer and Pielke, 1975). However, in this study, a simple relationship

$$
H=\bar{H}+z_{g}(x, y),
$$

is assumed.

The geostrophic wind components in (2) and (3) are given as

$$
\begin{aligned}
f U_{g} & \equiv f U_{g}(\bar{H}) \cdot\left\langle\Theta_{v}\right\rangle \cdot\left\langle\Theta_{v}(\bar{H})\right\rangle^{-1} \\
& +g\left(H-z_{g}\right)(\bar{H})^{-1} \int_{z^{*}}^{\bar{H}}\left\langle\Theta_{v}\right\rangle^{-1} \cdot \partial \Delta \Theta_{v} / \partial y \cdot d z^{\prime} \\
& +g(\bar{H})^{-1}\left(\partial H / \partial y-\partial z_{g} / \partial y\right) \int_{z^{*}}^{\bar{H}} \Delta \Theta_{v} d z^{\prime}
\end{aligned}
$$

and

$$
\begin{aligned}
f V_{g} & \equiv f V_{g}(\bar{H}) \cdot\left\langle\Theta_{v}\right\rangle \cdot\left\langle\Theta_{v}(\bar{H})\right\rangle^{-1} \\
& -g\left(H-z_{g}\right)(\bar{H})^{-1} \int_{z^{*}}^{\bar{H}}\left\langle\Theta_{v}\right\rangle^{-1} \partial \Delta \Theta_{v} / \partial x \cdot d z^{\prime} \\
& -g(\bar{H})^{-1}\left(\partial H / \partial x-\partial z_{g} / \partial x\right) \int_{z^{*}}^{\bar{H}} \Delta \Theta_{v} d z^{\prime}
\end{aligned}
$$

where $\Delta \Theta_{v}=\Theta_{v}-\left\langle\Theta_{v}\right\rangle$, and abbreviated symbols $U_{g}(\bar{H})=U_{g}(x, y, \bar{H}, t), V_{g}(\bar{H})=V_{g}(x, y, \bar{H}, t)$ etc. are used. For deriving (8) and (9), the hydrostatic equation, the Boussinesq approximation, and boundary conditions at $z^{*}=\bar{H} ; D U / D t=D V / D t$ $=0, U=U_{g}(\bar{H})$, and $V=V_{g}(\bar{H})$ are used (see the Appendix for detailed discussions).

Although simulation of clouds is not yet a major interest in this study, special attention should be given to the somewhat unconventional approach employed here for treatment of condensation and evaporation processes. The conservative variables, appropriate to the cases where phase changes occur but do not produce rain, are the liquid-water potential temperature (Betts, 1973)

$$
\Theta_{l} \equiv \Theta-(\Theta / T)\left(L / c_{p}\right) Q_{l},
$$

and the mixing ratio of the total water content

$$
Q_{w}=Q_{v}+Q_{l},
$$

where $\Theta$ is the potential temperature, and $Q_{v}$ and
$Q_{l}$ are the mixing ratios of water vapor and liquid water content, respectively. Detailed discussions, including derivations of the conservation equations of $\Theta_{l}$ and $Q_{w}$, are given in Yamada (1978a). The resulting equations, following the coordinate transformation, are

$$
\begin{aligned}
& D \Theta_{l} / D t=\partial\left(K_{x} \Theta_{l} / \partial x\right) / \partial x+\partial\left(K_{y} \partial \Theta_{l} / \partial y\right) / \partial y \\
& \quad+\bar{H}\left(H-z_{g}\right)^{-1} \partial\left(-\bar{w} \theta_{l}\right) / \partial z^{*},
\end{aligned}
$$

and

$$
\begin{aligned}
& D Q_{w} / D t=\partial\left(K_{x} \partial Q_{w} / \partial x\right) / \partial x \\
& \quad+\partial\left(K_{y} \partial Q_{w} / \partial y\right) / \partial y \\
& \quad+\bar{H}\left(H-z_{g}\right)^{-1} \partial(-\overline{w q} w) / \partial z^{*} .
\end{aligned}
$$

The vertical turbulent fluxes $\bar{u} \bar{w}, \overline{v w}, w \theta_{l}$ and $\bar{w} q_{w}^{-}$in (2), (3), (12) and (13) are computed from a set of simplified second-moment turbulence closure equations in which only a turbulence energy equation and a master length-scale equation (Mellor and Yamada, 1977) are solved prognostically. The turbulence energy equation is given by

$$
\begin{aligned}
& D\left(q^{2} / 2\right) / D t=\partial\left\{K_{x} \partial\left(q^{2} / 2\right) / \partial x\right\} / \partial x \\
& \quad+\partial\left\{K_{y} \partial\left(q^{2} / 2\right) / \partial y\right\} / \partial y \\
& \quad+\left\{\bar{H} /\left(H-z_{g}\right)\right\}^{2} \partial\left\{q l S_{q} \partial\left(q^{2} / 2\right) / \partial z^{*}\right\} / \partial z^{*} \\
& \quad-\bar{H}\left(H-z_{g}\right)^{-1}\left(u w \partial U / \partial z^{*}+\bar{v} w \partial V / \partial z^{*}\right. \\
& \quad+\beta g \overline{w \theta_{v}}-q^{3}\left(B_{1} l\right)^{-1}
\end{aligned}
$$

and the master length-scale equation is given by

$$
\begin{aligned}
& D\left(q^{2} l\right) / D t=\partial\left\{K_{x} \partial\left(q^{2} l\right) / \partial x\right\} / \partial x \\
& \quad+\partial\left\{K_{y} \partial\left(q^{2} l\right) / \partial y\right\} / \partial y \\
& \quad+\left\{\bar{H} /\left(H-z_{g}\right)\right\}^{2} \partial\left\{q_{l} S_{l} \partial\left(q^{2} l\right) / \partial z^{*}\right\} / \partial z^{*} \\
& \quad+l E_{1}\left[\overline { H } ( H - z _ { g } ) ^ { - 1 } \left(-\bar{u} \bar{w} \partial U / \partial z^{*}\right.\right. \\
& \left.\left.\quad-\overline{v w} \partial V / \partial z^{*}\right)+\beta g \bar{w} \theta_{v}\right] \\
& \quad-q^{3} B_{1}^{-1}\left[1+E_{2}(l / k z)^{2}\right] .
\end{aligned}
$$

The remaining turbulent second moments are obtained from a set of diagnostic equations; the final expressions for turbulent fluxes $\overline{u w}, \overline{v w}$, $\overrightarrow{w \theta}, \overline{w q_{w}}$ and $\overline{w \theta_{v}}$ are given elsewhere (Yamada, 1978a, b, and 1979). Thus, they are not repeated here.

In the previous study (Yamada, 1978b), the temperature at screen height was specified and solutions in approximately steady state were obtained. However, in this study, the surface temperature is determined by solving a heat conduction equation for soil layers. Therefore, the boundary conditions are discussed in detail in the following section. 


\section{Boundary conditions}

Surface boundary conditions for (2), (3), and (12) to (15) are constructed from the empirical formulas by Dyer and Hicks (1970) for the nondimensional wind and temperature profiles (see the Appendix). Strictly speaking, the formulas are valid only for horizontally homogeneous surfaces. It is assumed, however, that the same relations are fair approximations over nonhomogeneous terrain, provided that the formulas are applied sufficiently close to the surface. It should be noted that vegetation plays an active part in the apportionment of available heat energy between convective (sensible and latent) and conductive (into the soil) components. The technique discussed here is intended to address only the case of bare soil where the surface is conventionally characterized by roughness lengths. The complexity introduced by biological factors and drag forces due to tall trees (canopy flow) are beyond the scope of the present study. Use of the similarity formulas requires knowledge of the surface temperatures; a method to obtain the surface temperature is discussed below.

The temperature $T_{s}$ in the soil layer is obtained by solving the heat conduction equation

$$
\partial T_{s} / \partial t=\partial\left(k_{s} \partial T_{s} / \partial z_{s}\right) / \partial z_{s},
$$

where $z_{s}$ is positive downward, and soil diffusivity $k_{s}$ can be a function of soil moisture content. Appropriate boundary conditions for solution of (16) are the heat energy balance at the soil surface and specification of the soil temperature or soil heat flux at a depth dependent on the duration of the integration. The heat energy balance at the surface is given by

$$
R_{s}+R_{L \downarrow}-R_{L} \uparrow=H_{s}+L E+G_{s},
$$

where $R_{s}$ is the incoming solar radiation absorbed by the ground surface ( $R_{s}$ is zero in this study since only nocturnal cases are considered). $R_{L} \downarrow$ is the incoming longwave radiation, and $R_{L} \uparrow$ is the outgoing longwave radiation.

The surface heat flux $H_{s}$, latent heat flux $L E$ and ground heat flux $G_{s}$ are given by

$$
\begin{aligned}
& H_{s}=-\rho_{a} c_{p} u_{*} T_{*}, \\
& L E=-\rho_{a} L u_{*} Q_{*},
\end{aligned}
$$

and

$$
G_{s}=-k_{s} \partial T_{s} /\left.\partial z_{s}\right|_{G},
$$

where $\rho_{a}$ is the air density, $u_{*}$ is the friction velocity, $T_{*}$ is the temperature scale, $Q_{*}$ is the water vapor scale, and the subscript $G$ denotes the value at the ground surface. Substituting (18) to (20) into (17) we obtain

$$
\begin{aligned}
& R_{s}+\varepsilon R_{L} \downarrow-\varepsilon \sigma T_{G^{4}}=-\rho_{a} c_{p} u_{*} T_{*}\left(1+B^{-1}\right) \\
& \quad-k_{s} \partial T_{s} /\left.\partial z_{s}\right|_{G},
\end{aligned}
$$

where the relation

$$
R_{L} \uparrow=\varepsilon \sigma T_{G}{ }^{4}+(1-\varepsilon) R_{L \downarrow},
$$

and Bowen ratio

$$
B=H_{s} / L E,
$$

are used; $\varepsilon$ is the emissivity of the surface and $\sigma$ is the Stefan-Boltzman constant. Garratt and Hicks (1973) obtained a relationship between the surface temperature and air temperature at $z_{1}$ (in the surface layer):

$$
\begin{aligned}
& \left(\Theta\left(z_{1}\right)-\Theta_{G}\right) T_{*}^{-1}=\left(P_{r} / k\right)\left[\ln \left\{\left(z_{1}+z_{0 t}\right) / z_{0}\right\}\right. \\
& \left.\quad+\ln \left(z_{0} / z_{0 t}\right)-\phi\right],
\end{aligned}
$$

where $P_{r}$ is the turbulence Prandtl number at neutral stability, $k$ is the von Karman constant, $z_{o}$ and $z_{o t}$ are the roughness lengths for momentum and temperature, and $\phi$ is the stability correction terms of Panofsky (1963). A constant value of $0.1 \mathrm{~m}$ is assumed for $z_{o}$, and $z_{o t}$ is obtained from a relationship $\ln \left(z_{o} / z_{o t}\right)=2$ (Garratt and Hicks, 1973). Using (24) we can eliminate $T_{*}$ from (21) to obtain

$$
\begin{aligned}
& R_{S}+\varepsilon R_{L} \downarrow-\varepsilon \sigma T_{G}{ }^{4}+m\left[\Theta\left(z_{1}\right)-T_{G}\left(P_{0} / P_{G}\right)^{R / c_{p}}\right] \\
& \quad+k_{s} \partial T_{s} /\left.\partial z_{s}\right|_{G}=0,
\end{aligned}
$$

where

$$
\begin{aligned}
m= & k \rho_{a} c_{p} u_{*}\left(1+B^{-1}\right) P_{r}^{-1}\left[\ln \left\{\left(z_{1}+z_{0 t}\right) / z_{0}\right\}\right. \\
& +2-\phi]^{-1} .
\end{aligned}
$$

$P_{0}$ is a reference pressure $(1000 \mathrm{mb})$ and $P_{G}$ is the pressure at the surface. Equation (25) may be linearized by noting that

$$
\left(T_{G}{ }^{n+1}-T_{G}^{n}\right) / T_{G}{ }^{n} \ll 1,
$$

where the superscripts $n$ and $n+1$ denote the $n$ and $(n+1)$ th time steps of integration (a typical time increment used in integration is 1 min). After substitution into (25) of the approximation

$$
\left(T_{G}^{n+1}\right)^{4} \approx 4\left(T_{G^{n}}\right)^{3} T_{G^{n+1}}-3\left(T_{G}^{n}\right)^{4},
$$

we obtain

$$
\begin{aligned}
& {\left[4 \varepsilon \sigma\left(T_{G}^{n}\right)^{3}+m\left(P_{0} / P_{G}\right)^{R / c_{p}}+k_{s} / \Delta z_{s}\right] T_{G}{ }^{n+1}} \\
& \quad=\left(k_{s} / \Delta z_{s}\right) T_{s}^{n+1}(1)+R_{s}+\varepsilon R_{L} \downarrow \\
& \quad+3 \varepsilon \sigma\left(T_{G}{ }^{4}\right)^{4}+m \Theta^{n}\left(z_{1}\right)
\end{aligned}
$$

where the derivative $\partial T_{s} /\left.\partial z_{s}\right|_{G}$ is replaced by a forward finite-difference approximation $\left(T_{s}{ }^{n+1}\right.$ (1) $\left.-T_{G}{ }^{n+1}\right) / \Delta z_{s}, T_{s}(1)$ is the soil temperature at the first grid level from the surface, and $\Delta z_{s}$ is the distance between the surface and the first 
grid level in the soil layer.

Equation (16) is solved numerically in finitedifference form by Laasonen (Richtmyer and Morton, 1967, p. 189). By this method (16) reduces to $A T_{s}=\boldsymbol{B}$ where $\boldsymbol{A}$ is a tridiagonal matrix and $\boldsymbol{B}$ is a column vector. The solution is conveniently obtained by using the relation (Richtmyer and Morton, 1967, p. 198).

$$
\left(T_{s}\right)_{l}=E_{l}\left(T_{s}\right)_{l+1}+F_{l},
$$

where $\left(T_{s}\right)_{l}$ is the soil temperature at the $l$-th grid level from the surface. Expressions for $E$ and $F$ when $l>1$ are determined from the finitedifference form of (16), and (28) determines $E_{1}$ and $F_{1}$. From (28) and (29), we obtain

$$
\begin{aligned}
E_{1} & =\left(k_{s} / \Delta z_{s}\right) /\left[4 \varepsilon \sigma\left(T_{G}^{n}\right)^{3}+m\left(\boldsymbol{P}_{0} / \boldsymbol{P}_{G}\right)^{R / c_{p}}\right. \\
& \left.+k_{s} / \Delta z_{s}\right],
\end{aligned}
$$

and

$$
\begin{aligned}
F_{1}= & {\left[\boldsymbol{R}_{s}+\varepsilon R_{L \downarrow} \downarrow+3 \varepsilon \sigma\left(\boldsymbol{T}_{G}^{n}\right)^{4}+m \Theta^{n}\left(z_{1}\right)\right] } \\
& /\left[4 \varepsilon \sigma\left(\boldsymbol{T}_{G}\right)^{3}+m\left(\boldsymbol{P}_{0} / \boldsymbol{P}_{G}\right)^{R / c_{p}}+\left(k_{s} / \Delta z_{s}\right)\right] .
\end{aligned}
$$

Numerical integration of (16) by use of (29) to (31) is rapid, since no iteration is required.

Finally, the longwave incoming radiation at the surface is parameterized according to Swinbank's empirical formula (quoted in Paltridge and Platt, 1976, p. 139).

$$
R_{L \downarrow} \downarrow=5.31 \times 10^{-13} T^{6} \cos \alpha,
$$

where $R_{L} \downarrow$ is in $\mathrm{W} \mathrm{m}^{-2}, T$ is the screen temperature and $\alpha$, the angle of inclination of a sloped surface, is obtained from

$$
\alpha=\tan ^{-1}\left[\left(\partial z_{g} / \partial x\right)^{2}+\left(\partial z_{g} / \partial y\right)^{2}\right]^{1 / 2}
$$

Numerical values of the parameters $\varepsilon, k_{s}$, etc. used in the actual simulations are given following a definition of each parameter in Nomenclature.

\section{Initial values}

As is often done in numerical simulations to avoid computational shock, the ground is initially assumed to be flat and is modified gradually with time. Accordingly, horizontally homogeneous fields are initially assumed for all the variables to be integrated. The initial wind, and water vapor profiles (Fig. 3) are constructed from the profiles observed at PDC (Fig. 4) at midnight on 22 July, 1979. The maximum height of measurements by tethered sondes was $525 \mathrm{~m}$ above the ground. Thus, the profiles above this level are extrapolated from the values at lower heights. The mixing ratios in the layers above $1000 \mathrm{~m}$

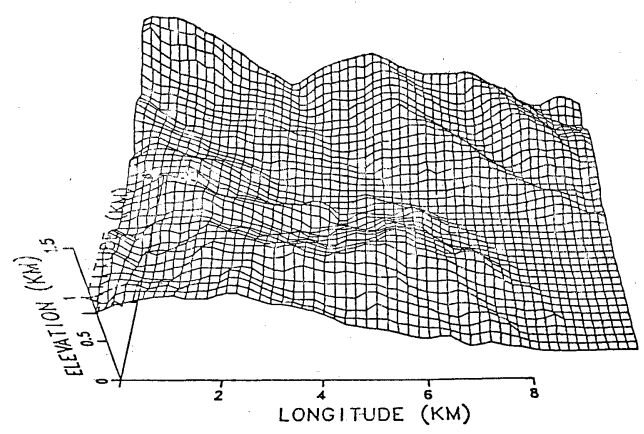

Fig. 2 Three-dimensional presentation of the area simulated.
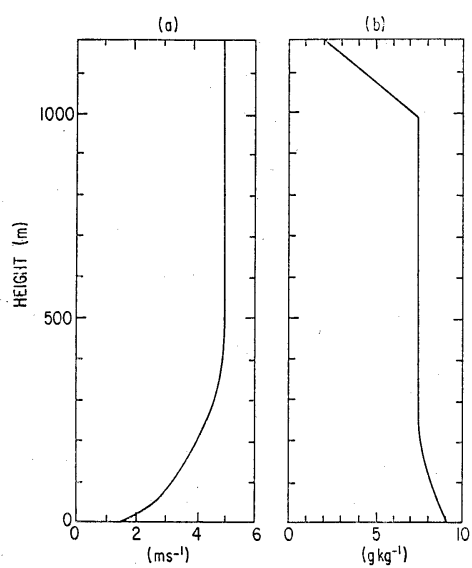

Fig. 3 Initial profiles of a) wind and b) mixing ratio of water vapor.

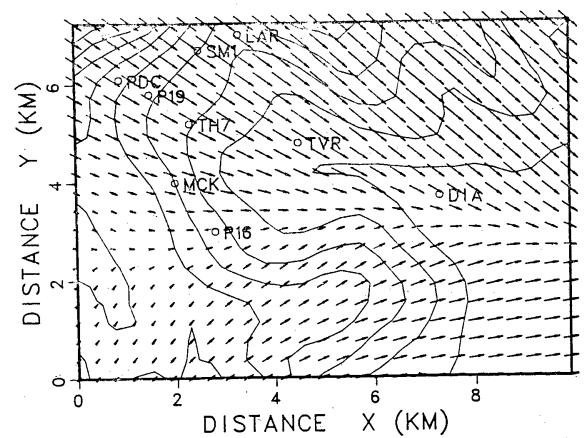

Fig. 4 Computed wind vectors at $68 \mathrm{~m}$ above the ground. Symbols in the figure indicate observational sites. Terrain is contoured by solid lines with an increment of $100 \mathrm{~m}$; the lowest contour is at $400 \mathrm{~m}$ above the mean sea level.

are assumed to decrease linearly with heights and approach a constant value. Relative humidity near the ground is assumed to be $50 \%$, consistent with the value observed. The tempera- 
tures in the soil layers are initially assumed to be constant $(302 \mathrm{~K})$. The potential temperatures in the atmosphere increase gradually with height from the ground values $(302 \mathrm{~K})$ to $305 \mathrm{~K}$ at height of $231 \mathrm{~m}$, and above that level the potential temperatures remain constant. All the turbulence variables are initialized by using Level 2 model of Mellor and Yamada (1974). The Level 2 model is an algebraic model obtained by neglecting time dependent, advection and diffusion terms in the turbulence energy equation given by (14).

\section{Numerical procedures}

Following coordinate transformation by Eq. (1), procedures of numerical integration become similar to those for flow over flat terrain (Yamada, 1978a). Therefore, only a brief description of the numerical procedures is given here. The prognostic equations (2), (3) and (12) to (15) are solved by using an Alternating Direction Implicit (ADI) method (Peaceman and Rachford, 1955), where integrations are performed in one direction at a time (Yamada, 1978a). The ADI method is numerically stable according to a linear stability analysis, but the time increment is chosen to satisfy the CourantFriedrichs-Lewy criteria.

In order to increase the accuracy of finitedifference approximations and to suppress computational noise; mean and turbulence variables are defined on a staggered grid, both horizontally and vertically (see Fig. 2 in Yamada, 1978a). Mean wind, temperature and water vapor vary greatly with height near the surface, but much less so away from the surface. In order to resolve these variations, vertical grid levels are determined according to a log-plus-linear relationship between the grid level and the vertical coordinate (Table 1). A grid of $27 \times 20 \times 9$ points is used to cover a computational region of approximately $10 \mathrm{~km} \times 7 \mathrm{~km} \times 1.3 \mathrm{~km}$. The locations of the vertical grid levels for the soil layers are also determined according to a log-plus-linear relationship (Table 1).

The vertical velocity $W^{*}$ is obtained by integrating the continuity equation (4) from the ground upward. A no-slip boundary conditions, $W^{*}=0$ at the ground, is used. The vertical wind is assumed to vanish along the top boundary. If $W^{*}$ is not zero, minor adjustments are applied to the horizontal wind components $U$ and $V$ in order to satisfy the boundary condition (Yamada, 1978a). Unlike the Level 2 model of Mellor
Table 1. Locations of the vertical grid levels used for atmospheric and soil layers.

\begin{tabular}{|c|c|c|c|}
\hline & $\begin{array}{c}\text { Level } \\
\#\end{array}$ & $\begin{array}{l}\text { Level } \\
\text { (m) }\end{array}$ & $\begin{array}{l}\text { Intermediate } \\
\text { level } \\
\text { (m) }\end{array}$ \\
\hline \multirow{13}{*}{ 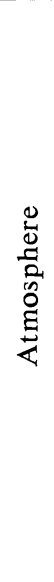 } & 9 & 1280 & \multirow[b]{2}{*}{1182} \\
\hline & & & \\
\hline & 8 & 1085 & \multirow{2}{*}{988} \\
\hline & 7 & 891 & \\
\hline & 6 & 698 & 794 \\
\hline & & & \multirow[t]{2}{*}{602} \\
\hline & 5 & 508 & \\
\hline & 4 & 322 & 414 \\
\hline & & & \multirow[t]{2}{*}{231} \\
\hline & 3 & 145 & \\
\hline & & & \multirow[t]{2}{*}{68} \\
\hline & 2 & 15 & \\
\hline & & & 0.8 \\
\hline \multirow{13}{*}{$\overline{\tilde{D}}$} & & & \multirow[t]{2}{*}{0.003} \\
\hline & 2 & 0.009 & \\
\hline & 3 & 0.054 & 0.024 \\
\hline & & & \multirow[t]{2}{*}{0.100} \\
\hline & 4 & 0.159 & \\
\hline & & & \multirow[t]{2}{*}{0.228} \\
\hline & 5 & 0.303 & \\
\hline & 6 & 0.466 & 0.383 \\
\hline & & & \multirow[t]{2}{*}{0.551} \\
\hline & 7 & 0.638 & \\
\hline & & & \multirow[t]{2}{*}{0.727} \\
\hline & 8 & 0.817 & \\
\hline & 9 & 1.0 & 0.907 \\
\hline
\end{tabular}

and Yamada (1974) the present model does not cut off turbulence even when the flux Richardson number exceeds a critical value of approximately 0.21 . However, eddy viscosity coefficients become very small when the flux Richardson number exceeds the critical value. A lower limit of $10^{-4} \mathrm{~m}^{2} \mathrm{~s}^{-1}$ is imposed if eddy viscosity coefficients become smaller than the lower limit.

In this model, the lateral boundaries in south and west are designated inflow boundaries and the north and east boundaries are outflow boundaries. In other words, only the cases when inflow is between southerly and westerly are simulated. Since observations are not available at the inflow boundaries, boundary values are generated by numerical simulation of a onedimensional (vertical) version of the governing 
equations (2), (3) and (12) to (15). The values at the outflow boundaries are obtained by linear extrapolation from the values one and two grid points inside from the boundary.

Variables $U, V, Q_{w}, \Theta_{l}, q^{2}$, and $q^{2} l$ are smoothed at each time step by using the values at four neighboring points, i.e.,

$$
\begin{aligned}
& \phi_{i, j}=\lambda \phi_{i, j}+0.25 \lambda\left(\phi_{i_{+1}, j}+\phi_{i, j+1}\right. \\
& \left.\quad+\phi_{i-1, j}+\phi_{i, j-1}\right)
\end{aligned}
$$

where $\phi$ represents one of the variables and $\lambda=0.5$ is used.

\section{Results and discussions}

Integration is initiated at 0000 PST and continued for 3 hours. During this period simulated wind fields nearly obtain a steady state and the terrain variations in the model attain $99.5 \%$ of the values shown in Fig. 2. Since a staggered grid system (Section 6) is used, all variables are not computed at the same points. However, for convenience in presenting the results, variables are interpolated to common grids. Figure 4 shows the distribution of horizontal wind vectors on a terrain-following surface, $68 \mathrm{~m}$ above the ground. A grid point is located at the center of each arrow. The length of an arrow is proportional to the wind speed: an arrow of one grid length indicates $10 \mathrm{~m} \mathrm{~s}^{-1}$. A simulation with a westerly geostrophic clearly shows downslope flow converging into a valley (Fig. 4). Drainage winds simulated along the slopes in the northwest are much larger than those in the southwest, primarily due to the difference in steepness. Horizontal winds at $68 \mathrm{~m}$ above the slopes in the northwest and south depart as much as 45 degrees from the generally westerly winds at $231 \mathrm{~m}$ (Fig. 5). Observed horizontal winds at $10 \mathrm{~m}$ above the ground are shown in Fig. 6. The simulated surface winds (Fig. 4) qualitatively

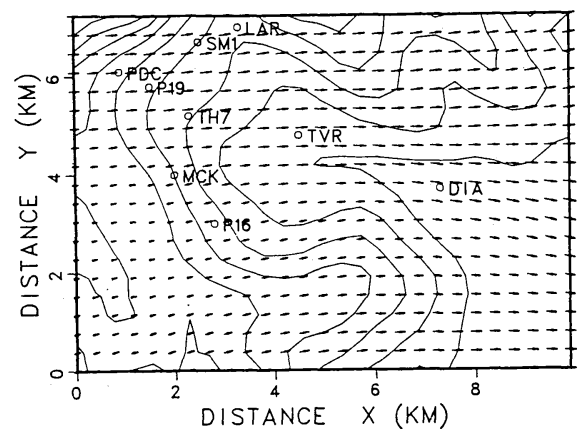

Fig. 5 Same as in Fig. 4 except at $231 \mathrm{~m}$ above the ground,

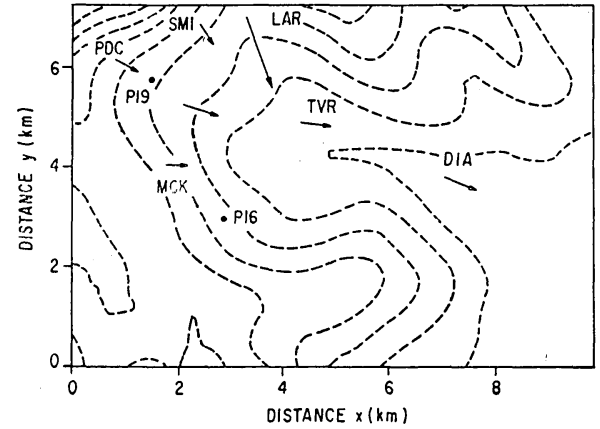

Fig. 6 Observed wind vectors at $10 \mathrm{~m}$ above the ground, averaged over the entire experimental period. The wind vector at LAR represents approximately $10 \mathrm{~m} \mathrm{~s}^{-1}$.

agree with those observed (Fig. 6). However, the observed wind speeds are much smaller except at LAR (Fig. 6), where agreement is reasonably good. The primary cause for the overprediction of surface wind speeds is attributed to the irregular coverage of trees of typical height $20 \mathrm{~m}$. Thus, drainage flow may have been decreased considerably by the drag due to trees. Although the immediate vicinities of observation towers are relatively clear, most observation sites are surrounded by trees. A minimum fetch needed before the flow becomes free from the effect of upstream trees is at least 100 times the tree height. The station at LAR most nearly approaches satisfaction of the fetch requirement. This might explain why the highest wind speeds

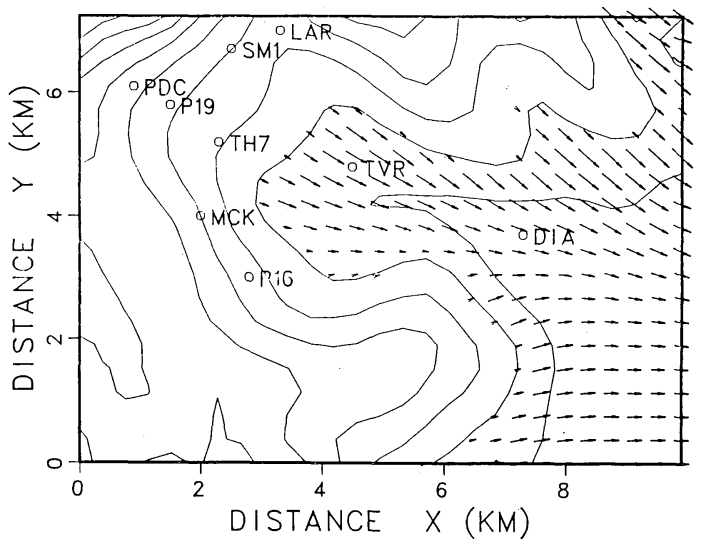

Fig. 7 Computed horizontal wind vectors $200 \mathrm{~m}$ above the lowest point in the area. Terrain is contoured by solid lines with an increment of $100 \mathrm{~m}$; the lowest contour is at $400 \mathrm{~m}$ above the mean sea level. 
are measured at this station.

Winds simulated in the terrain-following coordinate system are interpolated at $200 \mathrm{~m}, 400 \mathrm{~m}$, and $550 \mathrm{~m}$ above the lowest elevation $(308 \mathrm{~m}$ msl) (Figs. 7, 8, and 9, respectively). The veering of wind with height is clearly indicated. For example, Fig. 8 shows that wind direction near the ground approximate the slope of terrain, but change rather rapidly with height to approach the westerly geostrophic wind.

Acceleration (deceleration) and convergence (divergence) of the horizontal wind vectors result in vertical winds, which can be computed from the mass conservation equation. Distribution of the vertical wind component at $145 \mathrm{~m}$ above the ground is shown in Fig. 10. Maximum downward motion is found over the downslope, while maximum upward motion is computed at the convergence zone over the valley. It is cautioned that the vertical motion presented here should be interpreted only qualitatively, as there has been no verification by observation. The magnitude of simulated vertical motion is a function of the height of the upper computational boundary, since vertical motion is assumed to vanish there (see Section 6). Measurements of vertical motion are urgently needed, since vertical motion and horizontal meandering are particularly important for realistic simulation of pollutant transport over the Geysers area.

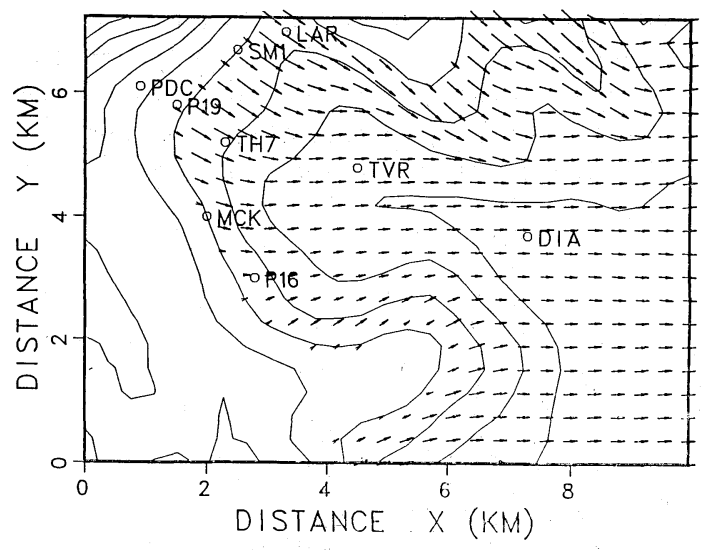

Fig. 8 Same as in Fig. 7 except at $400 \mathrm{~m}$ above the lowest point.

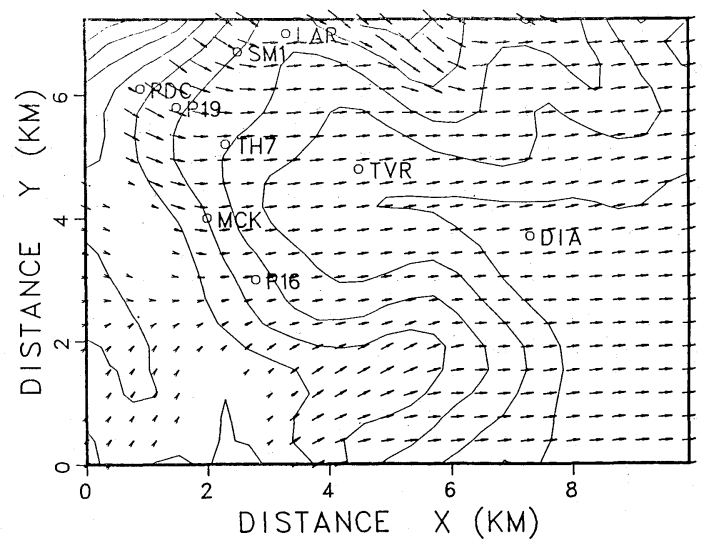

Fig. 9 Same as in Fig. 7 except at $550 \mathrm{~m}$ above the lowest point.

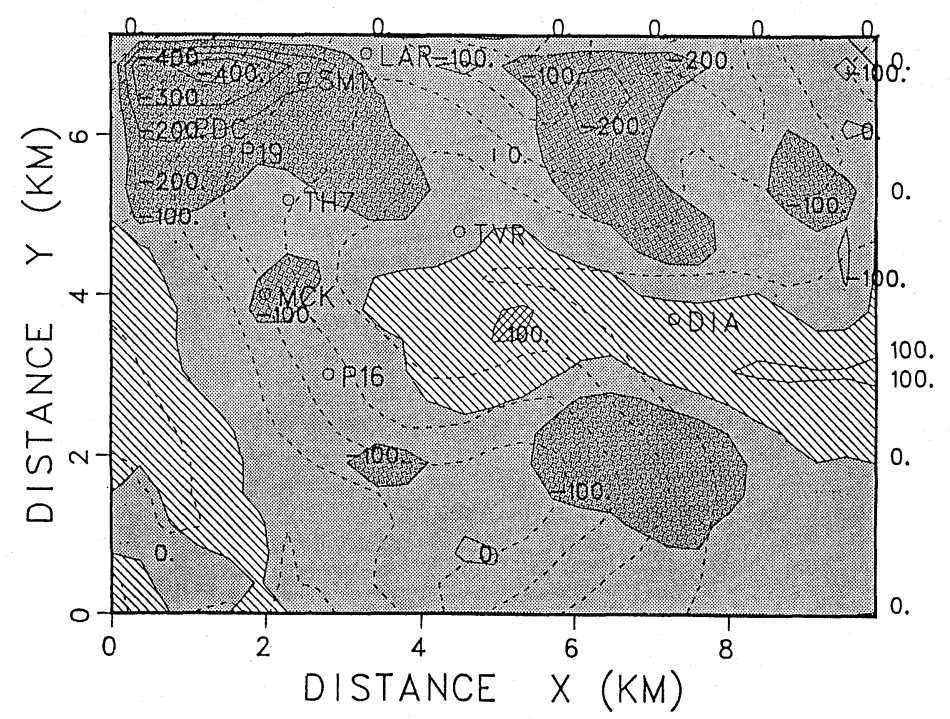

Fig. 10 Computed vertical velocities $\left(\mathrm{cm} \mathrm{s}^{-1}\right)$ at $145 \mathrm{~m}$ above the ground. 
Vertical profiles of the horizontal wind speed in the cross-section through the line $\mathrm{C}-\mathrm{C}$ in Fig. 11 are shown in Fig. 12. Profiles near the ground are not precise, due to the rather coarse grid resolution in the vertical direction. Nevertheless, these profiles clearly indicate wind maxima in the surface layer and weak minima in the layer above. Development of drainage flow along the slope is also evident. The upstream wind profile at the far left is almost uniform with height, but wind maxima typical to drainage flow become evident as flow travels downslope. These profiles indicate that the nocturnal drainage flow layer is very thin. According to analytical solutions for one-dimensional slope flow (Sutton, 1953), wind maxima occur at $\pi l / 4$ above the ground where

$$
l^{4}=4\left(K_{M} K_{H}\left\langle\Theta_{v}\right\rangle / \gamma g\right) \operatorname{cosec}^{2} \delta .
$$

In this expression $K_{M}$ and $K_{H}$ are eddy viscosity and eddy diffusivity, respectively; $\gamma$ is a lapse rate of the potential temperature profile in the

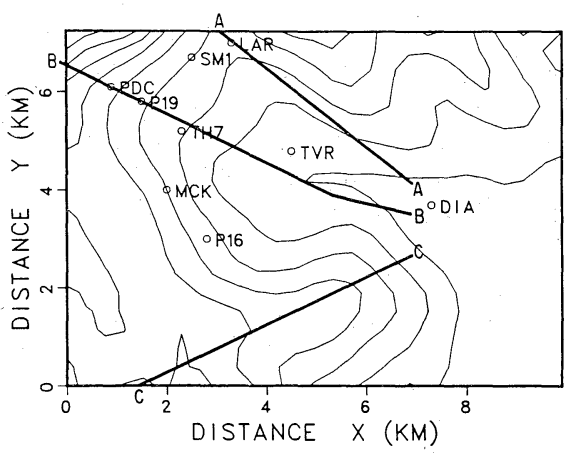

Fig. 11 A map to show the locations of the cross sections used in Figs. 12 to 14.

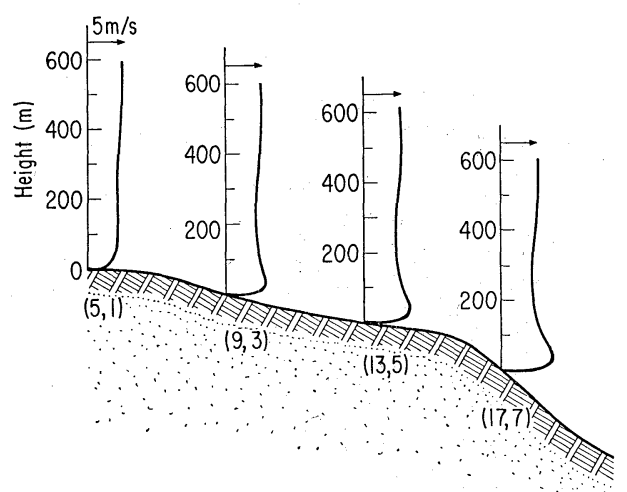

Fig. 12 Computed wind speed profiles in the vertical plane through $\mathrm{C}-\mathrm{C}$ in Fig. 11. Exact locations are given by grid coordinates $(\mathrm{I}, \mathrm{J})$. surface inversion layer, and $\delta$ is the ground slope. Substituting $K_{M}=K_{H}=2 \mathrm{~m}^{2} \mathrm{~s}^{-1}$ and $\gamma=$ $0.04 \mathrm{~K} \mathrm{~m}^{-1}$ obtained from the simulation, and a ground slope $\delta=10$ degrees into the above expression, one obtains $l=25 \mathrm{~m}$. Thus, wind maxima are expected to occur at $23 \mathrm{~m}$ above the ground. The wind speed profiles (Fig. 13) in the vertical plane through the line A-A of Fig. 11 indicate wind maxima approximately $50 \mathrm{~m}$ above the ground. Simulated speeds of $8 \mathrm{~m} \mathrm{~s}^{-1}$ at $10 \mathrm{~m}$ above the ground agree with the observation at LAR. Figure 14 shows the wind speed profiles in the vertical cross-section through the line B-B (Fig. 11). For example, a wind speed vertical profile measured by tethered sondes at station TH7 is shown in Fig. 15. Large differences between observed and simulated wind speed profiles are noted. Computed profiles (Fig. 14) exhibit maxima near the surface, typical for drainage flow, while the observed profiles are relatively uniform with height. It

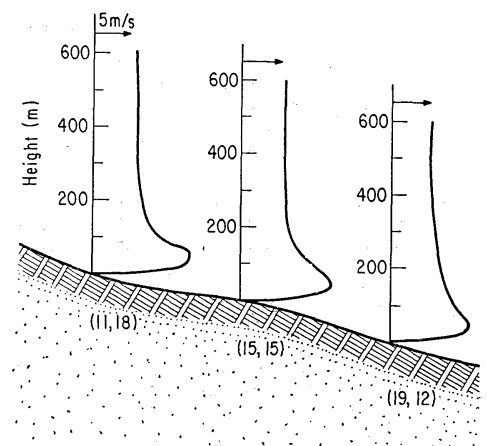

Fig. 13 Same as in Fig. 12 except in the vertical plane through A-A in Fig. 11.

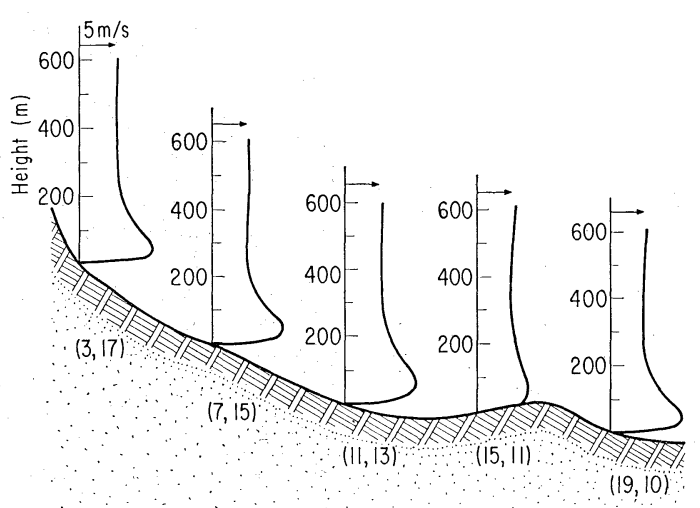

Fig. 14 Same as in Fig. 12 except in the vertical plane through $B-B$ in Fig. 11. 


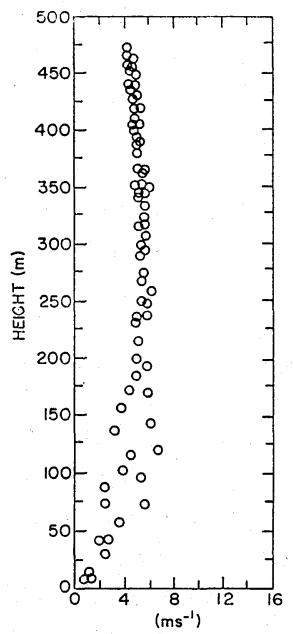

Fig. 15 Observed wind speed profile at PDC at 0400 PST.

is not immediately clear the reason why the observations do not exhibit the maxima predicted by theory for one-dimensional slope flow and numerical simulations. This may be due to inadequate vertical resolution in observed data, or to physical effects not considered, such as canopy drag. One way to remove the difficulty, i.e., a direct computation of tree drag, might be to simulate only the flow away from the canopy using, as surface boundary conditions, log-linear profiles for wind, temperature and water vapor with roughness lengths and displacement heights taking the tree heights into consideration. In order to know the profiles of the corresponding variables within the canopy, this model would require empirically determined similarity profiles. However, such similarity profiles within a canopy and over a sloping surface have not been developed yet.

Temperature distributions at the surface and $230 \mathrm{~m}$ above the ground are shown in Figs. 16 and 17 , respectively. In general, simulated temperatures over the downslope surfaces are higher than those over a valley. The distribution of temperatures is correlated well with that of the simulated vertical wind (Fig. 10): when the atmosphere is stably stratified downward motion transports potentially warm air, resulting in the area of higher potential temperature and upward motion transports potentially cool air, resulting in the area of minimum potential temperature. Thus, the vertical motion, as well as turbulent and radiational heat transfers, plays an important role in determining the potential temperature

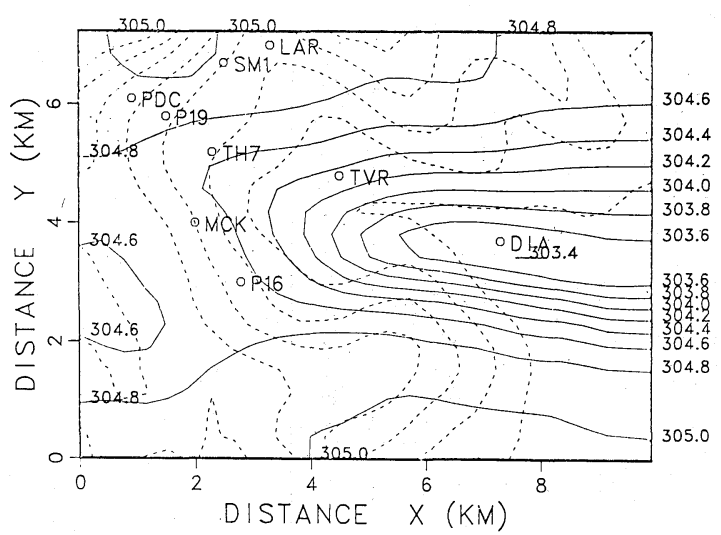

Fig. 16 Computed potential temperature (K) at the surface. Symbols in the figure and terrain contours are the same as in Fig. 4.

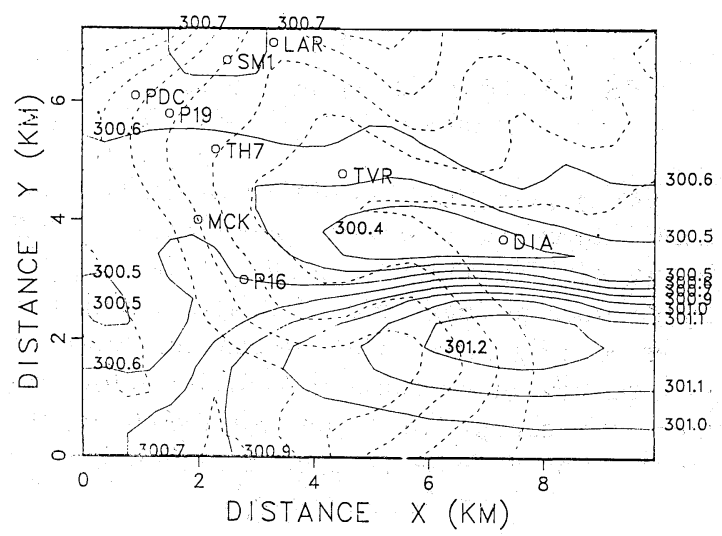

Fig. 17 Same as in Fig. 16 except at $231 \mathrm{~m}$ above the ground.
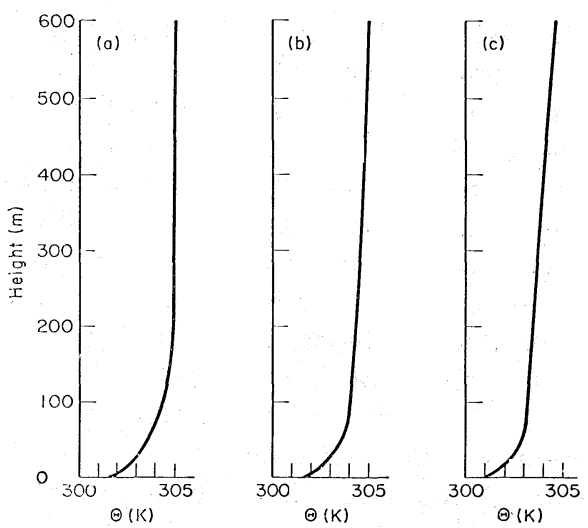

Fig. 18 Computed potential temperature profiles in a vertical plane through B-B in Fig. 11. Exact locations are given by grid coordinates $(\mathbf{I}, \mathrm{J})$. a) $(3,17)$, b) $(11,13)$, and c) $(19,10)$. 


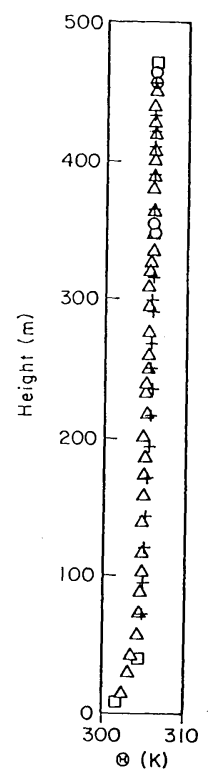

Fig. 19 Observed potential temperature profile at PDC at 0400 PST.

profiles. Figure 18 shows profiles of the potential temperatures in a vertical plane through B-B in Fig. 11. The simulated profile of the potential temperature at PDC (Fig. 18a) agrees well with observed (Fig. 19). This agreement, however, may be fictitious because the effects of the surface tree canopy were not considered in the model. For a dense canopy, maximum cooling due to longwave radiation occurs somewhere near the crown height of trees rather than at the ground, resulting in a stable boundary layer above a canopy, and a slightly unstable or near neutral layer within a canopy. Thus, a layer of main drainage flow could be displaced above a tree canopy, which may explain an elevated wind maximum at approximately $100 \mathrm{~m}$ above the ground (Fig. 15). Therefore, it is very important to consider the effects of a tree canopy into the model in order to simulate realistically both wind and temperature profiles in the Geysers area. Continuous efforts have been made to include into the model both aerodynamic and radiational effects of a tree. However, this is beyond the scope of the present study.

\section{Summary and conclusions}

Nocturnal drainage flow over the California Geysers area has been simulated with a threedimensional, simplified second-moment turbulence-closure model. The simulation of nocturnal drainage flow, horizontal convergence in the valley and resulting vertical motions appears to be reasonable. Wind speed profiles exhibit increasingly large maxima in the surface layer as the flow travels downslope. Large maxima and weak minima in the simulated wind speed profiles are consistent with theoretical predictions for one-dimensional slope flow. On the other hand, observed speeds are much smaller and more uniform with height. It is quite possible that the measurements of wind profiles by tethered sondes might have missed or oversmoothed wind maxima confined to a thin layer $(<50 \mathrm{~m})$ near the surface, due to a rather coarse vertical resolution. It is also speculated that the observed drainage flow may have been decreased considerably by drag induced by trees surrounding most observational sites. This speculation is partially supported by recent measurements of drainage flow in Australia over a slope with sparse tree coverage (Manins and Sawford, 1979). Their wind profiles clearly show large maxima similar to the ones predicted here. This appears to suggest that an increase of the vertical resolution in the model would not improve the agreement between computed results and observations in the Geysers area. The effects of tall trees (canopy flow) should be taken into account, through further development of numerical models such as the present one.

\section{Acknowledgements}

The work is supported by the U.S. Department of Energy. The author is grateful to J. Shannon and I. Lee who carefully read the manuscript and gave constructive suggestions. P. Gudikson of Lawrence Livermore Laboratory kindly provided Fig. 6, and T. Horst of Pacific Northwest Laboratory Figs. 15 and 19. The author is also indebted to R. Spencer for her excellent typing of a manuscript.

\section{Appendix}

Equations of motion in the transformed coordinate system

The hydrostatic equilibrium using the Boussinesq approximation may be given as (e.g., Yamada, 1978a)

$$
0=-\langle\rho\rangle^{-1} \partial P / \partial z-\left[1-\beta\left(\Theta_{v}-\left\langle\Theta_{v}\right\rangle\right)\right] g,
$$

where $\rho$ is the air density, $P$ is the pressure, $\Theta_{v}$ is the virtual potential temperature and $\beta$ is the thermal expansion coefficient, $\left(1 /<\Theta_{v}>\right)$. The bracket $\langle>$ indicates an average taken over a horizontal plane. It is found convenient to 
eliminate the density from the equation of It is noted that the approximation (A11a) is motion by using the equation of state.

First let us define a modified pressure,

$$
\Pi \equiv C_{p}\left(P / P_{0}\right)^{x}
$$

where $P_{0}$ is a reference pressure $(1000 \mathrm{mb})$. Differentiating (A2) logarithmically by $x_{i}$, we obtain after rearrangement

$$
\partial P / \partial x_{i}=(P / k \Pi) \cdot \partial \Pi / \partial x_{j} .
$$

Substituting into (A3) the virtual potential temperature

$$
\Theta_{v}=\left(P_{0} / P\right)^{\ltimes} T_{v}=C_{p} \Pi^{-1} T_{v},
$$

and dividing by $\langle\rho\rangle$ both sides of the resultant equation, one obtains

$$
\langle\rho\rangle^{-1} \partial P / \partial x_{i}=\rho\langle\rho\rangle^{-1} \bullet \Theta_{v} \bullet \partial \Pi / \partial x_{i},
$$

where the equation of state $P=\rho R_{d} T_{v}$ and a relationship $\kappa C_{p}=R_{d}$ are used. A ratio $\rho^{\bullet}\langle\rho\rangle^{-1}$ may be rewritten as

$$
\begin{aligned}
& \rho \cdot\langle\rho\rangle^{-1}=1+\Delta \rho \cdot\langle\rho\rangle^{-1}=1-\Delta \Theta_{v} \cdot\left\langle\Theta_{v}\right\rangle^{-1} \\
& \quad=1-\beta\left(\Theta_{v}-\left\langle\Theta_{v}\right\rangle\right) .
\end{aligned}
$$

Substituting (A6) into (A5), we obtain

$$
\langle\rho\rangle^{-1} \partial P / \partial x_{i}=\left[1-\beta\left(\Theta_{v}-\left\langle\Theta_{v}\right\rangle\right)\right] \Theta_{v} \partial \Pi / \partial x_{i} .
$$

Thus, Eq. (A1) can be rewritten as

$$
\partial \Pi / \partial z=-g / \Theta_{v} .
$$

where the term $\langle\rho\rangle^{-1} \partial P / \partial z$ is eliminated by using (A7) for $x_{3}=z$. The hydrostatic equation in the transformed coordinate system may be obtained by performing a chain differentiation of (A8), resulting

$$
\begin{gathered}
\partial \Pi / \partial z^{*}=(\partial \Pi / \partial z) \cdot\left(\partial z / \partial z^{*}\right) \\
=-g\left(H-z_{g}\right)\left(\bar{H} \Theta_{v}\right)^{-1},
\end{gathered}
$$

where Eqs. (1c) and (A8) are used.

The pressure gradient in the $x$ direction is obtained from (A7)

$$
\begin{aligned}
\langle\rho\rangle^{-1} \partial P / \partial x & =\left[1-\beta\left(\Theta_{v}-\left\langle\Theta_{v}\right\rangle\right)\right] \Theta_{v} \partial \Pi / \partial x \\
& \cong\left\langle\Theta_{v}\right\rangle \partial \Pi / \partial x,
\end{aligned}
$$

where an approximation

$$
\begin{aligned}
{[1} & \left.-\beta\left(\Theta_{v}-\left\langle\Theta_{v}\right\rangle\right)\right] \Theta_{v} \\
& =\left\langle\Theta_{v}\right\rangle\left(1-\Delta \Theta_{v}\left\langle\Theta_{v}\right\rangle^{-1}\right)\left(1+\Delta \Theta_{v}\left\langle\Theta_{v}\right\rangle^{-1}\right) \\
& =\left\langle\Theta_{v}\right\rangle\left[1-\left(\Delta \Theta_{v} /\left\langle\Theta_{v}\right\rangle\right)^{2}\right] \\
& \cong\left\langle\Theta_{v}\right\rangle,
\end{aligned}
$$

is used, Equation (A11a) is a good approximation since under normal conditions

$$
\left(\Delta \Theta_{v} /\left\langle\Theta_{v}\right\rangle\right)^{2} \ll 1,
$$

where

$$
\Delta \Theta_{v} \equiv \Theta_{v}-\left\langle\Theta_{v}\right\rangle .
$$
consistent with the accuracy of the Boussinesq approximation used in the equations of motion. The RHS of (A10) may be rewritten in the transformed coordinate system as

$$
\begin{aligned}
& \left\langle\Theta_{v}\right\rangle \partial \Pi / \partial x \\
& \quad=\left\langle\Theta_{v}\right\rangle \partial \Pi / \partial x+\left\langle\Theta_{v}\right\rangle \partial \Pi / \partial z^{*} \cdot \partial z^{*} / \partial x \\
& =\left\langle\Theta_{v}\right\rangle \partial \Pi / \partial x-g\left\langle\Theta_{v}\right\rangle\left(H-z_{g}\right)\left(\bar{H} \Theta_{v}\right)^{-1} \times \\
& {\left[\left(z^{*}-\bar{H}\right)\left(H-z_{g}\right)^{-1} \cdot \partial z_{g} / \partial x\right.} \\
& \left.\quad-z^{*}\left(H-z_{g}\right)^{-1} \cdot \partial H / \partial x\right] \\
& =\left\langle\Theta_{v}\right\rangle \partial \Pi / \partial x-g\left\langle\Theta_{v}\right\rangle\left(z^{*}-\bar{H}\right)\left(\bar{H} \Theta_{v}\right)^{-1} \\
& \quad \cdot \partial z_{g} / \partial x+\left\langle\Theta_{v}\right\rangle \Theta_{v}^{-1} \cdot g \cdot\left(z^{*} / \bar{H}\right) \cdot \partial H / \partial x,
\end{aligned}
$$

where (A9) and the following relationship obtained by differentiating (1) by $x$, i.e.,

$$
\begin{gathered}
\partial z^{*} / \partial x=\left(z^{*}-\bar{H}\right)\left(H-z_{g}\right)^{-1} \cdot \partial z_{g} / \partial x \\
-z^{*}\left(H-z_{g}\right)^{-1} \cdot \partial H / \partial x
\end{gathered}
$$

are used. Thus, the equation of motion in the $x^{*}$ direction is

$$
\begin{aligned}
& D U / D t-f V=-\left\langle\Theta_{v}\right\rangle \partial \Pi / \partial x \\
& \quad+g\left\langle\Theta_{v}\right\rangle\left(z^{*}-\bar{H}\right)\left(\bar{H} \Theta_{v}\right)^{-1} \partial z_{g} / \partial x \\
& \quad-g\left\langle\Theta_{v}\right\rangle z^{*}\left(\bar{H} \Theta_{v}\right)^{-1} \partial H / \partial x+\ldots
\end{aligned}
$$

where the turbulent diffusion terms are omitted until the final expression (A25) is obtained. The pressure $\Pi$ in (A14) can be obtained by integrating (A9) from $z^{*}$ to $\bar{H}$, i.e.,

$$
\begin{aligned}
& \Pi\left(x, y, z^{*}, t\right)=\Pi(x, y, \bar{H}, t) \\
& \quad+\left(H-z_{g}\right)(\bar{H})^{-1} \cdot g \int_{z^{*}}^{\bar{H}} \Theta_{v}^{-1} d z^{\prime} .
\end{aligned}
$$

Differentiation of (A15) by $x$ yields,

$$
\begin{aligned}
& \partial \Pi / \partial x=\partial \Pi(\bar{H}) / \partial x+g\left(H-z_{g}\right)(\bar{H})^{-1} \\
& \quad \times \partial\left(\int_{z^{*}}^{\bar{H}} \Theta_{v^{-1}} d z^{\prime}\right) / \partial x \\
& \quad+g\left(\partial H / \partial x-\partial z_{g} / \partial x\right)(\bar{H})^{-1} \int_{z^{*}}^{\Theta^{\bar{H}}} v^{-1} d z^{\prime} .
\end{aligned}
$$

where an abbreviated symbol $\Pi(\bar{H})=\Pi(x, y, \bar{H}, t)$ is used. The integration in the second term on the RHS of (A16) may be rewritten as

$$
\begin{aligned}
& \partial\left(\int_{z^{*}}^{\bar{H}} \Theta_{v^{-1}} d z^{\prime}\right) / \partial x \\
& \quad=\int_{z^{*}}^{\bar{H}}\left(\partial \Theta_{v^{-1}} / \partial x\right) d z^{\prime},
\end{aligned}
$$

where the Leipnitz rule of exchanging integration and differentiation, and $\partial \bar{H} / \partial x=0$ are used. Deviations of $\Theta_{v}$ from $\left\langle\Theta_{v}\right\rangle$ are small under normal conditions, i.e., $\Delta \Theta_{v} /\left\langle\Theta_{v}\right\rangle \ll 1$, so that 
following approximation holds:

$$
\Theta_{v}^{-1} \cong\left\langle\Theta_{v}\right\rangle^{-1}\left(1-\Delta \Theta_{v} \cdot\left\langle\Theta_{v}\right\rangle^{-1}\right) \text {. }
$$

where $\Delta \Theta_{v}$ is already defined by (A11c). Differentiation of (A18) by $x$ yields

$$
\partial \Theta_{v}{ }^{-1} / \partial x \cong-\left\langle\Theta_{v}\right\rangle^{-2} \cdot \partial \Delta \Theta_{v / \iota:}
$$

Substituting (A19) into (A17), we obtain

$$
\begin{aligned}
& \partial\left(\int_{z^{*}}^{\bar{H}} \Theta_{v}^{-1} d z^{\prime}\right) / \partial x \\
& \quad=-\int_{z^{*}}^{\bar{H}}\left\langle\Theta_{v}\right\rangle^{-2} \cdot \partial \Delta \Theta_{v} / \partial x \cdot d z^{\prime}
\end{aligned}
$$

The integration in the third term on the RHS of (A16) is also approximated by using a relationship (A18), resulting in

$$
\begin{aligned}
\int_{z^{*}}^{\bar{H}} \Theta_{v}{ }^{-1} d z^{\prime} & \cong\left\langle\Theta_{v}\right\rangle^{-1} \\
& {\left[\left(\bar{H}-z^{*}\right)-\int_{z^{*}}^{\bar{H}} \Delta \Theta_{v} d z^{\prime}\right] }
\end{aligned}
$$

where $\left\langle\Theta_{v}\right\rangle$ is assumed to be independent with height. This assumption is not in general true. However, the errors which might result from using the approximation (A21) are probably not very significant.

Substituting (A20) and (A21) into (A16), we obtain after rearrangement

$$
\begin{aligned}
\partial \Pi & / \partial x=\partial \Pi(\bar{H}) / \partial x-g\left(\bar{H}-z^{*}\right)(\bar{H})^{-1} \\
& \times\left\langle\Theta_{v}\right\rangle^{-1} \partial z_{g} / \partial x+g\left\langle\Theta_{v}\right\rangle^{-1}(\bar{H})^{-1}\left(\bar{H}-z^{*}\right) \\
& \times \partial H / \partial x-g\left(H-z_{g}\right)(\bar{H})^{-1} \\
& \times \int_{z^{*}}^{\bar{H}}\left\langle\Theta_{v}\right\rangle^{-2} \cdot \partial \Delta \Theta_{v} / \partial x \cdot d z^{\prime} \\
& -g\left\langle\Theta_{v}\right\rangle^{-1}(\bar{H})^{-1}\left(\partial H / \partial x-\partial z_{g} / \partial x\right) \\
& \times \int_{z^{*}}^{\bar{H}} \Delta \Theta_{v} d z^{\prime} .
\end{aligned}
$$

Substituting (A22) into the equation of motion (A14), we obtain

$$
\begin{aligned}
& D U / D t-f V=-\left\langle\Theta_{v}\right\rangle \partial \Pi(\bar{H}) / \partial x \\
& \quad-g\left(\bar{H}-z^{*}\right)(\bar{H})^{-1}\left[\left\langle\Theta_{v}\right\rangle \Theta_{v}-1-1\right] \partial z_{g} / \partial x \\
& -g\left[\left\langle\Theta_{v}\right\rangle z^{*} \Theta_{v}-1(\bar{H})^{-1}+\left(\bar{H}-z^{*}\right)(\bar{H})^{-1}\right] \\
& \quad \times \partial H / \partial x+g\left(H-z_{g}\right)(\bar{H})^{-1} \\
& \quad \times \int_{z^{*}}^{\bar{H}}\left\langle\Theta_{v}\right\rangle^{-1} \cdot \partial \Delta \Theta_{v} / \partial x \cdot d z^{\prime} \\
& \quad+g(\bar{H})^{-1}\left(\partial H / \partial x-\partial z_{g} / \partial x\right) \int_{z^{*}}^{\bar{H}} \Delta \Theta_{v} d z^{\prime}
\end{aligned}
$$

The following conditions along the top boundary $\left(z^{*}=\bar{H}\right)$ are assumed: $V=V_{g}(\bar{H}), D U / D t=0$ and $\left\langle\Theta_{v}(\bar{H})\right\rangle=\Theta_{v}(\bar{H})$ where $V_{g}$ is the y component of the geostrophic wind. Substituting these boundary conditions into (A23), we obtain after rearrangement

$$
\left\langle\Theta_{v}(\bar{H})\right\rangle \partial \Pi(\bar{H}) / \partial x=f V_{g}(\bar{H})-g \cdot \partial H / \partial x .
$$

Eliminating $\partial \Pi(\bar{H}) / \partial x$ in (A23) by using (A24), we finally obtain the following $x$ component of equation of motion after rearrangement

$$
\begin{aligned}
& D U / D t=f\left(V-V_{g}\right)+g\left(\bar{H}-z^{*}\right)(\bar{H})^{-1} \\
& \quad \times\left[1-\left\langle\Theta_{v}\right\rangle \Theta_{v}{ }^{-1}\right] \partial z_{g} / \partial x \\
& \quad+g\left[\left\langle\Theta_{v}\right\rangle\left\langle\Theta_{v}(\bar{H})\right\rangle^{-1}\right. \\
& \left.\quad-\left(\left\langle\Theta_{v}\right\rangle \Theta_{v}{ }^{-1}-1\right) z^{*}(\bar{H})^{-1}-1\right] \cdot \partial H / \partial x \\
& \quad+\partial\left(K_{x} \partial U / \partial x\right) / \partial x+\partial\left(K_{x y} \partial V / \partial y\right) / \partial y \\
& \quad+\bar{H}\left(H-z_{g}\right)^{-1} \partial(-\bar{u} w) / \partial z^{*}
\end{aligned}
$$

where

$$
\begin{aligned}
f V_{g} & \equiv f V_{g}(\bar{H}) \cdot\left\langle\Theta_{v}\right\rangle \cdot\left\langle\Theta_{v}(\bar{H})\right\rangle^{-1} \\
& -g\left(H-z_{g}\right)(\bar{H})^{-1} \int_{z^{*}}^{\bar{H}}\left\langle\Theta_{v}\right\rangle^{-1} \cdot \partial \Delta \Theta_{v} / \partial x \cdot d z^{\prime} \\
& -g(\bar{H})^{-1}\left(\partial H / \partial x-\partial z_{g} / \partial x\right) \int_{z^{*}}^{\bar{H}} \Delta \Theta_{v} d z^{\prime}
\end{aligned}
$$

In a similar fashion, the $y$ component of equation of motion is obtained (Eq. 3).

\section{Boundary conditions}

The boundary conditions in the surface layer are obtained from the following formulas:

$$
\begin{aligned}
& \frac{V(z)}{u_{*}}=\frac{1}{k}\left[\ln \left\{\left(z+z_{0}\right) / z_{0}\right\}-\Psi_{m}(\zeta)\right], \quad(\mathrm{A} 27) \\
& \left.\frac{\Theta_{l}(z)-\Theta_{l}(0)}{T_{*}}=\frac{\boldsymbol{P}_{r}}{k}\left[\ln \left\{z+z_{0 t}\right) / z_{0} t\right\}-\Psi_{h}(\zeta)\right],
\end{aligned}
$$

$$
\begin{aligned}
& \frac{Q_{w}(z)-Q_{w}(0)}{Q_{*}}=\frac{S_{c}}{k}\left[\ln \left\{\left(z+z_{0 v}\right) / z_{0 v}\right\}\right. \\
& \left.-\Psi_{v}(\zeta)\right], \\
& q^{2}(z)=B_{1}{ }^{2 / 3} u_{*}{ }^{2}\left(\Phi_{m}-\zeta\right)^{2 / 3}
\end{aligned}
$$

and

$$
q^{2} l(z)=k z q^{2}(z) .
$$

In the above equations, $V(z), \Theta_{l}(z)$, and $Q_{w}(z)$ are the abbreviations for $V(x, y, z, t), \Theta_{l}(x, y, z, t)$, and $Q_{w}(x, y, z, t)$, respectively and $V$ is the horizontal wind speed $\left(U^{2}+V^{2}\right)^{1 / 2}$. Terms $u^{*}, T_{*}$, and $Q_{*}$, defined as $u_{*} \equiv \sqrt{ } \tau / \rho, \quad T_{*} \equiv H / \rho c_{p} u_{*}$, and $Q_{*} \equiv E / \rho u_{*}$, are friction velocity and scales for temperature and water vapor, respectively. Terms $\tau, H$, and $E$ are surface stress, total sensible heat, and rate of evaporation, respectively; total sensible heat being defined as $H=$ $\overline{w \theta_{v}}=\left(1+0.61 Q_{w}\right) w \theta+0.61 w \overline{q_{w}}$. The parame- 
ter $\zeta$ is a nondimensional height $z / L$, where $L$ is the Obukhov length $-u_{*}{ }^{3} / k \beta g H ; k$ is the von Karman constant; $z_{o}, z_{o t}$, and $z_{o v}$ are roughness lengths for wind, temperature, and water vapor, respectively; and $P_{r}$ and $S_{c}$ are the turbulence Prandtl and Schmidt numbers, respectively. Terms $\Psi_{m}, \Psi_{h}$, and $\Psi_{n}$ (Panofsky, 1963) are correction terms for the atmospheric stability and their functional forms are given by

$$
\begin{aligned}
& \Psi_{m}(\zeta)=\int_{0}^{\zeta}\left(1-\Phi_{m}\left(\zeta^{\prime}\right)\right) / \zeta^{\prime} d \zeta^{\prime}, \\
& \Psi_{h}(\zeta)=\int_{0}^{\zeta}\left(1-\Phi_{h}\left(\zeta^{\prime}\right)\right) / \zeta^{\prime} d \zeta^{\prime},
\end{aligned}
$$

and

$$
\Psi_{v}(\zeta)=\int_{0}^{\zeta}\left(1-\Phi_{v}\left(\zeta^{\prime}\right)\right) / \zeta^{\prime} d \zeta^{\prime},
$$

where $\Phi_{m}, \Phi_{h}$ and $\Phi_{v}$ are nondimensional wind, temperature, and water vapor gradients, respectively. The following formulations (Dyer and Hicks, 1970) are used for $\Phi_{m}, \Phi_{h}$, and $\Phi_{v}$ under unstable conditions,

$$
\begin{aligned}
& \Phi_{m}(\zeta) \equiv\left(u_{*} / k z\right)(\partial U / \partial z)=(1-15 \zeta)^{-1 / 4} \\
& \Phi_{h}(\zeta) \equiv\left(T_{*} / k z\right)\left(\partial \Theta_{l} / \partial z\right)=(1-15 \zeta)^{-1 / 2}
\end{aligned}
$$

and

$$
\Phi_{v}(\zeta) \equiv\left(Q_{*} / k z\right)\left(\partial Q_{w} / \partial z\right)=(1-15 \zeta)^{-1 / 2} .
$$

For stable conditions

$$
\Phi_{m}(\zeta)=\Phi_{h}(\zeta)=\Phi_{v}(\zeta)=1+5 \zeta . \quad(\mathrm{A} 38 \mathrm{a}, \mathrm{b}, \mathrm{c})
$$

The roughness lengths $z_{o}, z_{o t}$, and $z_{o v}$ are specified over land.

The boundary conditions at the top are assumed to be

$$
\begin{aligned}
& \partial U / \partial z=\partial V / \partial z=0, \\
& \partial \Theta_{l} / \partial z=0, \\
& \partial Q_{w} / \partial z=0, \\
& q^{2}=0,
\end{aligned}
$$

and

$$
\partial\left(q^{2} l\right) / \partial z=0 .
$$

\section{List of Symbols and Numerical Values Used}

$C_{p}$ : specific heat capacity of dry air at constant pressure, 1.003 joules $\mathrm{g}^{-1} \mathrm{k}^{-1}$

$E_{1}, E_{2}$ : empirical constants in a length scale equation (15), $E_{1}=1.8$ and $E_{2}=1.33$ from Mellor and Yamada (1977)

$k$ : Von Karman constant, 0.4

$k_{s}$ : soil diffusivity, $1.11 \times 10^{-6} \mathrm{~m}^{2} \mathrm{~s}^{-1}$
$L$ : latent heat of water vapor, 2500 joules $\mathrm{g}^{-1}$

$l:$ a master turbulence length scale

$P$ : pressure

$P_{0}:$ a reference pressure, $1000 \mathrm{mb}$

$P_{r}$ : turbulent Prandtl number for neutral condition, 1.0

$q^{2}:$ twice the turbulence energy, $\sum \overline{u_{i} u_{i}}$

$q_{w}$ : fluctuation of mixing ratio of total water $Q_{v}, Q_{l}, Q_{w}$ : mean mixing ratios of water vapor, liquid water and total water

$R$ : gas constant for dry air, 0.28704 joules $\mathrm{g}^{-1} \mathrm{~K}^{-1}$

$u_{*}:$ friction velocity

$\widehat{u_{k} q_{w}}$ : turbulent moisture flux

$\overline{u_{k} u_{j}}$ : Reynolds stress

$\overline{u_{k} \theta_{l}}$ : turbulent heat flux

$\beta$ : thermal expansion coefficient, $\cong 1 / \Theta_{v}$

$\varepsilon$ : emissivity, 0.98

$\theta_{v}$ : fluctuation of virtual potential temperature

$\Theta_{l}$ : liquid potential temperature, $\equiv(\Theta-\Theta / T)\left(L / c_{p}\right) Q_{l}$

$\Theta_{v}$ : virtual potential temperature, $\equiv \Theta\left(1+0.61 Q_{w}-1.61 Q_{l}\right)$

$\kappa$ : ratio $R / c_{p}, 0.286$

$\sigma:$ Stefan-Boltzman constant, $5.67 \times 10^{-8}$ $\mathrm{W} \mathrm{m}^{-2} \mathrm{~K}^{-4}$

- : ensemble average

\section{References}

Anthes, R. A. and Warner, T. T., 1974: Prediction of mesoscale flows over complex terrain. ECOM, United States Army Electronics Command, Fort Monmouth, New Jersey 07703, ECOM-5532, $101 \mathrm{p}$.

Betts, A. K., 1973: Non-precipitation cumulus convection and its parameterization. Quart. J. Roy. Met. Soc., 99, 178-196.

Dyer, A. J. and B. B. Hicks, 1970: Flux-gradient relationships in the constant flux layer. Quart. J. Roy. Met. Soc., 96, 715-721.

Garratt, J. R. and B. B. Hicks, 1973: Momentum, heat and water vapour transfer to and from natural and artificial surfaces. Quart. J. Roy. Met. Soc., 99, 680-687.

Mahrer, Y. and R. A. Pielke, 1975: A numerical study of the air flow over mountains using the two-dimensional version of the University of Virginia mesoscale model. J. Atmos. Sci., 32, 2144-2155.

Manins, P.C. and B. L. Sawford, 1979: Katabatic winds: A field case. Quart. J. Roy. Met. Soc., 105, 1011-1025.

Mellor, G. L. and T. Yamada, 1974: A hierarchy of turbulence-closure models for planetary 
boundary layer. J. Atmos. Sci., 31, 1791-1806. and 1977: Turbulent Shear Flows, Pennsylvania State University, State College, PA., 6.1-6.14.

Nickerson, E. C., 1979: On the numerical simulation of airflow and clouds over mountains terrain. Beitr. Phys. Atmos., 52, 161-177.

O'Brien, J. J., 1970: A note on the vertical structure of the eddy exchange coefficient in the planetary boundary layer. J. Atmos. Sci., 27, 1213-1215.

Paltridge, G. W. and C. M. R. Platt, 1976: Radiative Processes in Meteorology and Climatology. Elsevier Scientific Publishing Company, New York, $318 \mathrm{p}$

Panofsky, H. A., 1963: Determination of stress from wind and temperature measurements. Quart. I. Roy. Met. Soc., 23, 85-93.

Peaceman, D. W. and H. H. Rachford, Jr. 1955: The numerical solution of parabolic and elliptic differential equations. J. Soc. Indust. Appl. Math., 3, 28-41.

Richtmyer, R. D. and K. W. Morton, 1967: Difference Methods for Initial-Value Problems, Second Ed., Interscience Publishers, J. Willey and Sons, New York, $405 \mathrm{pp}$.

Sutton, O. G., 1953: Micrometeorology. McGrawHill book company, New York, 333 pp.

Yamada, T., 1978a: A three-dimensional, secondorder closure numerical model of mesoscale circulations in the lower atmosphere. Argonne National Laboratory, ANL/RER-78-1, 67 pp. Available from National Technical Information Service, U.S. Department of Commerce, 5285 Port Royal Road, Springfield, VA 22161.

1978b: A three-dimensional numeri study of complex atmospheric circulations produced by terrain. Proceedings of Conference on Sierra Nevada Meteorology. American Meteorological Society, 61-67. 1979: An application of a three-dimensional, simplified second-moment closure numerical model to study atmospheric effects of a large cooling-pond. J. Atmos. Environ., 13, 693-704. and G. L. Mellor, 1979: A numerical simulation of BOMEX data using a turbulence closure model coupled with ensemble cloud relations. Quart. J. Roy. Met. Soc., 105, 915944.

\title{
夜間下降流の数值シミュレーション
}

\author{
山田哲 二 \\ Argonne National Laboratory, U.S.A.
}

米园カリフォルニア州の間欠泉地方で観測された夜間下降流をシミュレートするために三次元の Mesoscale 大気モデルが使われた。この数值モデルは以前冷水湖や簡単な形の山の大気の流れを計算するのに使われたもの を修正したものである。流体方程式を解くのに必要な乱流フラックスは乱流エネルギーと乱流スケールだけを偏 微分方程式で解くといら簡単化された乱流 closure 方程式から計算された。下降流，盆地上での水平方向の収 劒，その結果生じる上昇流等は定性的には観測と合う結果が得られた。しかしながら地表近くの風速は観測値よ りも大きく，これは観測の鉛直方向の resolution が不十分であるためか，あるいは森林による drag がモデル に考慮されていないためであると思われる。 